\title{
Bioanalysis
}

\section{Interview with Jana Zemenová}

Jana Zemenová talks to Sankeetha Nadarajah, Commissioning Editor: Jana is a PhD student of analytical chemistry in her final year at the University of Chemistry and Technology, Prague. She also works at the Institute of Organic Chemistry and Biochemistry of Czech Academy of Sciences, in the group led by Lenka Maletínská. She has obtained her MSc in Analysis of Drugs and continues working at University of Chemistry and Technology Prague under the supervision of David Sýkora.

Accepted for publication: 10 January 2017; Published online: 8 February 2017

Keywords: LC-MS • lipopeptides $\bullet$ review $\bullet$ young scientist

My scientific career started when I was at the University of Chemistry and Technology in Prague, where I obtained my Bachelor's degree in drug synthesis and production, after which I moved to the analytical world where I did my Master's degree in Analysis of Drugs. At this point my interest in lipopeptides began, as the main topic of my thesis was to develop a methodology for LC-MS to measure lipopeptides, which I did in co-operation with the Institute of Organic Chemistry and Biochemistry of the Czech Academy of Science in Prague. This was in order to get pharmacokinetic and stability data for the molecules that are to be used as therapeutics.

Q Please describe the work currently done at your institution.

At the Institute of Organic Chemistry and Biochemistry in the group of Lenka Maletínská, in which I am working, we are trying to develop novel compounds that can be used for the treatment of obesity, diabetes and also Alzheimer's disease. Right now we are carrying out preclinical-phase studies, and we are trying to prove that our lipopeptides are working. In our team, I am responsible for PK and stability measurements, working both with immunomethods and LC-MS.
Q Tell us about your recently accepted review on 'Lipopeptides as therapeutics: applications and in vivo quantitative analysis'.

I have been working with lipopetides for almost 5 years, and we found that the behavior of these compounds is not very usual, and gaining this experience was quite a painful experience. So we made a decision to try and review all the problems that may occur during the analysis of lipopeptides. As we had already done plenty of literature reviews and research, there was no reason for us not to put all the information together for someone else, and relieve them from making the same mistakes that we did.

Q How important a tool is MS in the study of lipopeptides, as their use as therapeutics seems to be expanding? Well, we started the analysis of lipopeptides with immunomethods, but we found out that the specificity or selectivity of immunomethods is actually quite low. Quite often there is false positivity in results from signals caused by smaller fragments of targeted peptide, with an unknown structure. I think that MS is better for this as, once again, it is a method which is sensitive enough, for example, to measure your PK concentrations, which is exactly what is needed, and you are able to

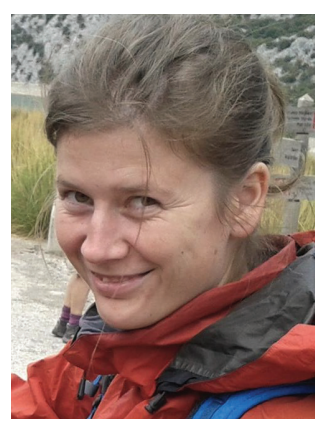

Jana Zemenova

Department of Analytical Chemistry, University of Chemistry \& Technology Prague, Technická 5, 16628 Prague, Czech Republic

and

Institute of Organic Chemistry \& Biochemistry, Academy of Sciences of the Czech Republic, Flemingovo nám. 2, 16610 Prague 6, Czech Republic jana.zemenova@gmail.com 
find out what the metabolites of your compounds are. I also think once you have the LC-MS instruments, it is even cheaper than immunomethods.

Q How has your experience been as a young scientist in the bioanalysis industry?

During my PhD, I think the most important thing was the guidance from the supervisors, the support from the institutions and the quality of the research project, which in my case were great. But what I feel as a lack of experience is that I have not had a chance to get industry experience. But I suppose that is owing to the fact that in the Czech Republic, it is hard to find such a department. So I am unsure about my future in the research field, and the advantages and disadvantages of working in academia as opposed to a commercial field.

Q What are your long-term scientific goals?

Being in my final year of $\mathrm{PhD}$ study, I would like to defend my thesis this year. After that I would like to go for a postdoctorate position. But right now I am not sure whether to stay in academia or go to work for a company, so I plan to apply for a postdoctorate position in a company and find out if the environment is suitable for me.

\section{Disclaimer}

The opinions expressed in this interview are those of the interviewee and do not necessarily reflect the views of Future Science Ltd.

\section{Financial \& competing interests disclosure}

J Zemenová is an employee of Institute of Organic Chemistry and Biochemistry and a student at University of Chemistry and Technology Prague. The author has no other relevant affiliations or financial involvement with any organization or entity with a financial interest in or financial conflict with the subject matter or materials discussed in the manuscript apart from those disclosed.

No writing assistance was utilized in the production of this manuscript. 